\title{
Placas pretibiales con atrofia central
}

\author{
Molinero Barranco M.A. ${ }^{1}$
}

Sanid. mil. 2011; 67 (2): 127-128; ISSN: 1887-8571

Niña de 11 años de edad, natural de Cañada Rosal, Sevilla. Entre los antecedentes personales cabe destacar el padecimiento de una diabetes tipo I, de un hipotiroidismo, de ser portadora de hemofilia y no presenta la menarquia. En los antecedentes familiares destaco la presencia de diabetes tipo II en la abuela materna. Nos comenta que desde hace 6 meses presenta unas manchas rojas en las piernas que no causan sintomatología subjetiva y que su médico trata como



Figura 1. Placas pretibiales. una micosis. A la exploración evidencio la presencia de unas placas rojo - parduzcas, de bordes irregulares, discretamente elevados, siendo el centro de la lesión de color amarillento con discreta atrofia y surcado por finas telangiectasias. Se ubican en el tercio medio de la región pretibial de ambas piernas. Realizada biopsia incisional de una de las placas, el informe histopatológico revela la presencia de granulomas necrobióticos.

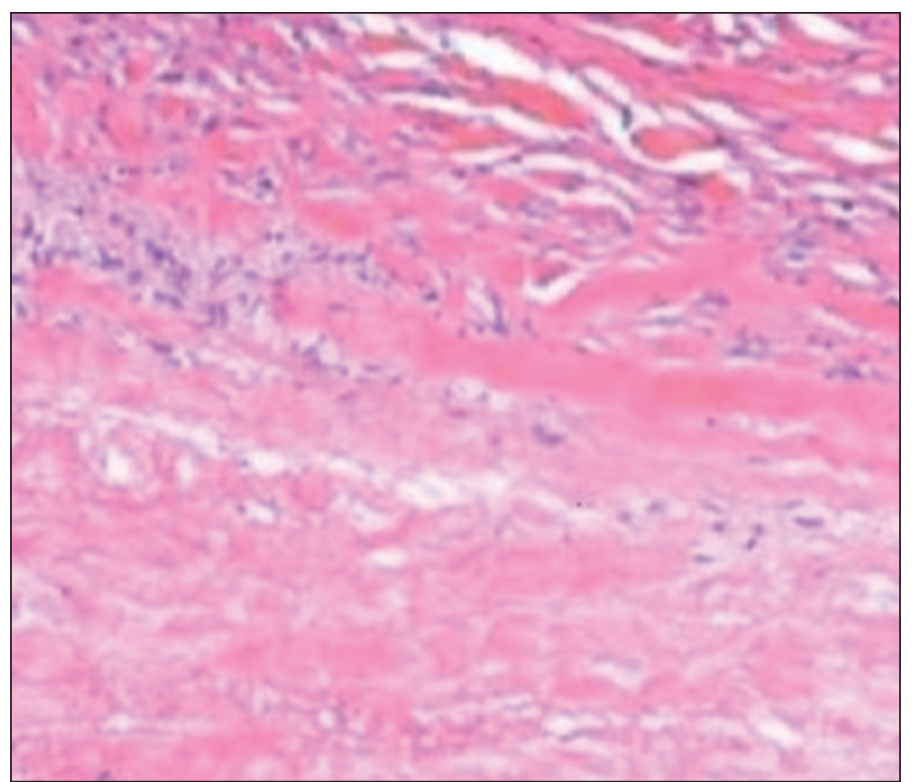

Figura 2. Zonas de necrosis en la dermis profunda.

${ }^{1}$ Tcol. Médico (retirado). Consulta privada. 


\section{Diagnóstico: Necrobiosis lipoídica diabeticorum}

Con los datos clínicos e histológicos se emite el juicio diagnóstico de necrobiosis lipoidica diabeticorum. Se trata con beclometasona tópicamente y se cita para sucesivas consultas de control de su evolución.

La necrobiosis lipoidica diabeticorum fue descrita por Urbach y Oppenheim en 1923 y 1929 respectivamente. Consiste en la necrosis del colágeno y en la presencia de granulomas en empalizada, asociados a enfermedades sistémicas, especialmente a diabetes mellitus en la que un $0,3 \%$ de los diabéticos la presentan ${ }^{1}$. También puede aparecer en artritis reumatoide, iritis, lupus eritematoso sistémico, enfermedad inflamatoria intestinal, vasculitis con ANCA positivos, tiroiditis y linfomas ${ }^{1}$. Suele afectar con mayor frecuencia a las mujeres adultas, aunque puede afectar a cualquier edad, como en el caso presentado, de ahí su interés.

Para la gran mayoría de autores, la etilogía es desconocida, argumentándose diversas teorías etiopatogénicas basadas en la microangiopatía diabética, y traumatismos que inciden en la zona ${ }^{1-4}$.

La clínica se caracteriza por la presencia de una mácula eritematosa que tiende a evolucionar centrífugamente, presentando un borde festoneado y discretamente elevado, con el centro de la lesión más pálido y atrófico con telangiectasias. Suelen afectar a la región pretibial aunque se han encontrado lesiones en el tegumento de los muslos, brazos y cuero cabelludo. Aquí pueden causar la atrofia de los folículos pilosebáceos dando lugar a la granulomatosis disciformis crónica y progresiva de Meischer (1948) ${ }^{3}$. Para Requena y Martín ${ }^{5}$ esta forma se considera en al actualidad como una dermo- patía que se incluye dentro del espectro del granuloma elastolítico. El número de lesiones que aparecen varía entre 2 y 8 . El control de la glucemia no influye en su aparición. El diagnóstico diferencial debemos establecerlo con la morfea, el granuloma anular, la sarcoidosis, el xantogranuloma necrobiotico y los nódulos reumatoideos. Histopatológicamente destaca la degeneración del colágeno rodeado de un infiltrado inflamatorio granulomatoso y con presencia de células espumosas y depósito de material lipoide.

El tratamiento es difícil, obteniendo distintos resultados con fármacos como los corticoides tópicos, los corticoides orales e intralesionales, fibrinolíticos, pentoxifilina, heparina, antiagregantes plaquetarios, ticlopidina y clofazimina. El tratamiento quirúrgico se plantea excepcionalmente en caso de ulceraciones crónicas, pudiendo extirpar las lesiones y aplicar un injerto de piel.

\section{BIBLIOGRAFÍA}

1. Velasco Pastor A.M. Necrobiosis lipoidica: actualización sobre su etiopatogenia y tratamiento. Rev Intern Dermatol Dermocosm 2002; 5: 342-47.

2. Alegre de Miquel V., Aliaga Boniche A.. Manifestaciones cutáneas de las alteraciones nutricionales, metabólicas y endocrinas en geriatría. Aula Médica S.A. Madrid 1997; 144-145.

3. Braun-Flaco O., Plewing G., Wolff H.H., Winkelmann K.. Dermatología. Springez-Verlag Ibérica. Barcelona 1995; 963-964.

4. Gay Prieto J.. Dermatología. Ed Científico Médica (8. a edición). Barcelona 1996; 499.

5. Requena Caballero L., Martín Moreno L.. Manifestaciones cutáneas de la diabetes mellitus. Jano 3-9 Mayo 1991; XL(960): 77-93. 